\title{
"A Study on The Levels Of Stress Among Post Graduate Students Of Dibrugarh University",
}

\section{${ }^{1}$ Sri Gaurab Pratim Hazarika,}

(M.A., M.Phil.), Assistant Professor, Mahapurusha Srimanta Sankaradeva Viswavidyalaya, Nagaon, Assam, India. Email IDgaurabhazarika07@gmail.com

\section{${ }^{2}$ Dr. (Mrs.) Neeta Kalita Barua,}

Professor, Department of Education, Dibrugarh University. Email ID- nkbarua_edu@dibru.ac.in

\begin{abstract}
:
Stress is normally an unavoidable part of everyone's life living in this world. It portrays a negative notion that can have an impact on one's mental and physical well-being. Stress is always regarded as a psychological process that involves an individual's personal interpretation and response to any threatening event. Stress is an unavoidable part of life everybody meet with stress in his/ her life; it can take a toll on students "e physical health, mental health, and academic success and even on every part of life unless they discover to cope with it appropriately. Stress has a negative impact on one's mental and physical wellbeing. Throughout a lifetime, one may experience thousands of different episodes of stress. It means that stress may be a normal, adaptive reaction to threat. Its role is to signal and prepare individuals to take defensive action. Take for instance, fear of things that present realistic threats motivates individuals to deal with them or avoid them. . College and Post Graduation students experience stress connected to changes in lifestyle, increased workload, new tasks, interpersonal relationships and a lot of other things. Tremendous levels of stress can hinder work efficacy and lead to meagre academic performance and at the same time it affects one's overall happiness.
\end{abstract}

Keywords:

Stress, Post Graduate students, Mental Heath, Workload, Happiness.

Article Received: 18 October 2020, Revised: 3 November 2020, Accepted: 24 December 2020

\section{0 INTRODUCTION}

Stress is always regarded as a psychological process that involves an individual's personal interpretation and response to any threatening event. The term Stress was coined by Hans Selye in 1936, who defined it as "the non- specific response of the body to any demand for change". Stress is becoming part of human life and every individual faces stress in their life. Stress has a negative impact on one's mental and physical wellbeing. Throughout a lifetime, one may experience thousands of different episodes of stress. The level of stress may vary from intense to minimal (Maheswari \& Deepa, 2013). It is important to note that stress can have both positive and negative effects on people. It means that stress may be a normal, adaptive reaction to threat. Its role is to signal and prepare individuals to take defensive action. Take for instance, fear of things that present realistic threats motivates individuals to deal with them or avoid them. Most psychologists assert that moderate stress motives individuals to achieve and fuels creativity, although stress may hinder individuals from performance on difficult tasks (Auerbach \& Grambling 1998). Everybody meets with stress in his/ her life; it can take a toll on students ${ }^{\text {ee }}$ physical health, mental health, and academic success and even on every part of life unless they discover to cope with it appropriately. College and Post Graduation students experience stress connected to changes in lifestyle, increased workload, new tasks, interpersonal relationships and a lot of other things. Tremendous levels of stress can hinder work efficacy and lead to meagre academic performance and at the same time it affects one's overall happiness. Such students who have experienced stressful life events also reported worse health outcomes and reduced quality of life most of the time. Alteration of student's 
environment from school surroundings to university surroundings could cause a mental, educational and social shock to them, since this didactic system has vast differences. The students have to countenance new methods of training, new atmosphere, new scholastic requirements, new kind of relations between students and faculties and even new relations among students themselves. Stress is one of the major facets of our contemporary life, resulted from the swift changes and modernity in human beings, so this period is called the age of stress. Students undergo from many stresses like educational stress resulted from testing and exams, home works and additional school necessities which may go beyond their abilities. Mothers have their own stress resulted from child schooling, workers, leaders, and whole society have diverse form of stress, sometimes the same person undergoes from different kinds of stress at one moment (Hussien and Hussien, 2006).

\subsection{THE TWO FACES OF STRESS}

Stress can be negative or positive, depending on the level of our response to the stressors we encounter. Apparently, most of us only think about the bad sides of stress. Negative stresses are actually about stresses that are beyond one's control. This bad impact of severe stress is often manifested in physical and mental signs and symptoms. However, when we are only exposed to mild or moderate stress, we are actually able to experience the good side of stress, which include improved creativity, learning, efficiency at work and, eventually, a higher level of self-esteem that could lead us to be able to withstand a higher stress levels in the future.

\subsection{EFFECTS OF STRESS}

It has been argued that an individual can have possibly anxious thoughts, difficulty to concentrate or remember because of being stressed. Stress can lead also to change in people's behaviours, such as nail biting, heavy breathing, teeth clenching and hand wringing. When people are stressed, they may feel cold hands and feet, butterflies in stomach, and sometimes-increased heart rate, which all are regarded as common physiological effects of stress, which can be connected to emotion of anxiety (Auerbach \& Gramling, 1998). Physical and psychological responses to stress generally occur together, principally when stressors become more intense. However, one category of stress responses can influence other responses. For instance, mild chest pain may lead to the psychological stress response of worrying about getting a heart attack. Physical responses can be when a person escapes from a terrible accident or some other frightening events, he or she will experience rapid breathing, increased heart beating, sweating, and even shaking little later. These reactions are part of a general pattern known as the fight-or-flight syndrome. The psychological responses to stress can appear as changes in emotions, thoughts (cognition), and behaviours (Bernstein et al., 2008).

\subsection{A BRIEF DESCRIPTION OF DIBRUGARH UNIVERSITY}

Dibrugarh University is a university in the Indian state of Assam. It was set up in 1965 under the provisions of the Dibrugarh University Act, 1965, enacted by the Assam Legislative Assembly. It is a teaching-cum-affiliating university with limited residential facilities. The university is situated at Rajabheta at a distance of about five kilometers to the south of Dibrugarh, a well known tea town of Upper Assam in northeastern India. Dibrugarh, which is one of the commercial and industrial hubs of the northeastern region, also occupies a unique place in the field of Art, Literature and Culture. Dibrugarh district known internationally as a rich tea producing district is also known for its rich reserve of minerals like coal, oil and natural gas. Its diverse flora and fauna makes it an exciting region from the point of view of environment and ecology. The various tribes which inhabit this district present a polychromatic ethnic mosaic and make it a very attractive destination for researchers from all over the globe. The Dibrugarh University campus is well connected by roads, rails, air and waterways. The National Highway No.37 passes through the 
University Campus. The territorial jurisdiction of Dibrugarh University covers seven districts of Upper Assam, viz, Dibrugarh, Tinsukia, Sivasagar, Jorhat, Golaghat, Dhemaji and Lakhimpur. The University Campus extends over an area of more than 500 acres. The University is accredited by National Assessment and Accreditation Council (NAAC) with an institutional score of $71 \%$ (B grade). The reaccreditation was last done in March 2009. Dibrugarh University is a member of the Association of Indian Universities (AIU) and recognized by all Universities in India and abroad on reciprocal basis.

The University through the various teaching Departments, Centers for Studies in its campus and the affiliated colleges scattered over the seven districts is imparting higher education in various branches of learning in Arts, Commerce, Engineering, Medical, Pharmaceutical Sciences, Law, Science \& Technology, Computer Sciences, Management, Sports and Teacher Training. The University campus hosts 17 Teaching Departments, 18 Centers for Studies and one Institute of Engineering and Technology (DUIET) organized under five different schools of studies leading to the M.A., M.Sc., M. Tech, M.Com., M.B.A, M. Pharm., M.Ed., M. L. Inf. Sc., MCA, Integrated M.Sc. in Physics, B.Ed., B. Pharm., B.B.A., B. Tech., 5- Year B.A. LL.B. (Hons), B.C.A., B. P. Ed., B.L.Inf.Sc., M. Phil and PhD degrees. Some of these Departments and Centers also conduct Diploma Courses like Tai- Language, Bodo language etc, besides the Post Graduate Diploma Programmes in Computer Application (PGDCA), Statistical Techniques and Computation (PGDSTC), Tea Technology and Plantation Management (PGDTTPM), Tourism Management (PGDTM), Journalism and Mass Communication (PGDJMC) etc. The University presently has around 200 affiliated and permitted colleges and institutes to achieve its goal of dissemination of knowledge and generation of human resource. It is also a matter of great pride that the only two colleges of the state, apart from the Cotton College, Guwahati, to have been granted the status of Autonomous Colleges by the UGC, India, fall under its jurisdiction; viz., the North Lakhimpur College, North Lakhimpur and the J. B. College, Jorhat.

\subsection{NEED AND SIGNIFICANCE OF THE STUDY}

In today's highly competitive world, students face various academic problems including exam stress, disinterest in attending classes and inability to understand the subject. In educational institution, more stress is given to the academic achievement of the students though various other outcomes are also expected. Thus, the expectation for high level of performance puts a lot of pressure on parents, teachers, administrators, students and as a whole educational system itself.

Stress is one of the serious issues that affect university student's life; its effects could be reflected in student social, academicals, and mental health. Linn and Zeppa (1984) found that stress can lead to academic decline, poor relationships with peers and family members and overall dissatisfaction with life. So each university has to assess its students stress in order to provide them with the suitable mental health care and the efficient methods to cope with stress. Higher education is one of the main factors that enable individuals to become successful in obtaining a profession in order to face the different challenges of life. College life can be challenging and difficult for a new student. However, it requires a higher degree of student initiative, determination, and self-monitoring. A huge amount of research has attempted to identify important factors of student's success by assessing the relations among many psychological and academic variables. Few studies have used different methods to propose and test models that can be used to understand the relations among factors that influence student's academic success.

The present study may develop insight to authorities so that they can find the reasons of stress in post graduate students of Dibrugarh University and the measures may be taken to prevent it. The post graduate students are in the 
highest step of formal educational ladder. They have to develop competition, guilt proneness, boldness, enthusiasm, sensitivity etc. Being the highest step of formal educational ladder the PG students represent a significant student group who can be handled by the peers and teachers at the last level of the formal education ladder. Understanding of stress is become very important because of the impact that may has on student's overall adjustment as well as their academic achievement.

Therefore, the present study was very significant to analyze the stress level of students of the post graduate level of Dibrugarh University. The investigator wanted to know how students perceive stress and how they cope with it on daily basis, as they are struggling to reduce and control the negative effects on their health and their academic performance. It is very important for postgraduate students to learn how to manage the stress, even if it cannot be eliminated. The findings may be useful in providing the opportunities and exposure for post graduate students for developing the healthy competitive feelings. Limited research has been done in this area. The study was carried out to find out how different stress can affect on students' day to day life. It will help teachers, parents and guidance workers in guiding and motivating the students as per their requirement. So, to increase the level of academic achievement of the post graduate students, findings of such researches help everyone related to the education system. This study would help the students to discover the various stressors affecting their day to day life. It will help the faculties in determining the stressors affecting their students and to guide the students in reducing the stress level so that they are more shaped and ready to face the challenges confidently. The study will also give an insight to the management to design and implement new programs that would facilitate in reducing the stress on students.

\subsection{TITLE OF THE STUDY}

The investigator titled the present study as "A

STUDY ON THE LEVELS OF STRESS AMONG POST GRADUATE STUDENTS OF DIBRUGARH UNIVERSITY"

\subsection{OBJECTIVES OF THE STUDY}

The investigator of the present study framed the following objectives:

1.6.1 To study the levels of stress of post graduate students of Dibrugarh University.

1.6.2 To suggest measures to overcome stress among students.

\subsection{DEFINITION OF IMPORTANT TERMS}

1.7.1 Stress: Stress can refer to experiencing events perceived as endangering one's physiological, physical or psychological wellbeing or a combination of these and when there is excessive pressure its intensity and chronic nature can lead to mental and physical ill health including depression, nervous breakdown and heart disease (Quick, Nelson and Hurrel, 1997).

1.7.2 Post Graduate students: Post Graduate students usually mean the group of students who have completed their under-graduate programmes and are enrolled in higher studies, usually in a University, for the postgraduate degree. In the context of the present study, Post Graduate students referred to the students studying in the 2 year CBCS programmes in the PG Departments of Dibrugarh University during the academic session 2016-2018.

\subsection{REVIEW OF RELATED \\ LITERATURE}

'College Chronic Life Stress Survey' constructed by Towbes and Cohen (1996) focuses on the frequency of chronic stress in the lives of college students. This scale contains items that persist across time to create stress, such as interpersonal conflicts, self-esteem problems, and money problems. These stressors were evaluated in relation to the number of times; a student had to deal with them on a weekly basis. It was found that with regard to chronic stress, first-year 
students scored higher than other students. RochaSingh (1994) has examined sources of stress among undergraduates through similar studies.

Do Dinh (2007) had conducted a study where she found that $1^{\text {st }}$ year medical students of University of Pharmacy and Medicine at HoChiMinh, Vietnam had experienced more stress related to Environmental, Intra-Personal and Academic area.

Ross, Niebling and Heckert (2008) conducted a study where the students from Midwestern University had experienced stress arising from all of the four major stressors i.e. Intra-Personal, Interpersonal, Academic and Environmental.

A study by Behere, Yadavand Behere (2011) found a higher level of stress among medical and engineering students. Similar finding was discovered by Yusoff, Rahim and Yaacob (2010) in the study of medical students at University Sains in Malaysia.

Mazumdar, Gogoi, Buragohain and Haloi (2012) conducted a comparative study on stress and its contributing factors among the graduate and post-graduate students of various colleges of Assam. From the study it was found in that the various symptoms which lead to stress mostly seen in more numbers in females as compared to males. It was also found that college students were highly affected by the stressful condition. Post graduate students were more susceptible to stress due to the increase in the responsibility than the graduate students.

Ghaderi, Kumar, Kumar (2009) Mysore University, Mysore conducted a study on Depression, Anxiety and Stress among the Indian and Iranian Students The data is collected from students studying in different departments of University of Mysore, studying post-graduate and Ph.D. degree courses. From the study it was found that Indian students were significantly more stressful than Iranian students and also genderwise a non significant difference was observed between male and female students.

Nandamuri and Gowthami (2009) did a study on sources of academic stress a study on management students. The major objective of the study was to explore the components of academic stress among the post graduate management students. From the study it was found that the components of academic activity were identified as - curriculum and instruction; team work; assessment; and placement and hence it was clearly identified that the components of academic work are responsible for academic stress among the management students.

\subsection{METHOD OF STUDY}

For the present study, the investigator had used the descriptive survey method for collection of data and other related information.

\subsection{TOOLS USED FOR THE STUDY}

According to the need of the study, the investigator had used the following tool for analyzing and interpretation of the data.

\subsubsection{Perceived Stress Scale: To} measure the level of stress "Perceived Stress Scale" by Cohen, Kamarch, \& Mermelstein, 1983 was used by the investigator. It is one of the most popular tools for measuring psychological stress. It is a self-reported questionnaire that was designed to measure "the degree to which individuals appraise situations in their lives as stressful" (Cohen et al., 1983, p. 385). The PSS items evaluate the degree to which individuals believe their life has been unpredictable, uncontrollable, and overloaded during the previous month. The assessed items are general in nature rather than focusing on specific events or experiences. There are three versions of the PSS. The original instrument is a 14 item scale (PSS14) that was developed in English (Cohen et al., 1983), with 7 positive items and 7 negative items rated on a 5-point Likert scale. The developer made the all three version of PSS available for free download from the internet means it is an open source tool. The investigator used the Perceived Stress Scale that has 14 items which is formally known as PSS-14. The reliability and validity of PSS-14 is as follows

Reliability: alpha $=.78$ 
Validity: Correlates in a predicted way with other measure of stress (Job Responsibilities Scale, life events scales).

Scaling: $0=$ Never; 1 = Almost Never; $2=$ Sometimes; 3 = Fairly often; 4 = Very often

Scoring $=$ PSS-14 scores are obtained by reversing the scores on the seven positive items, e.g., $0=4,1=3,2=2$, etc., and then summing across all 14 items. Items $4,5,6,7,9,10$, and 13 are the positively stated items.

\subsection{POPULATION OF THE STUDY}

The population of the present study comprised of all the Post-graduate students studying in the 17 Departments and 18 Centres of Dibrugarh University batch of students of the academic session 2015-17 and 2016-18.

\subsection{SAMPLE OF THE STUDY}

For the present study, 10 Departments of Dibrugarh University was selected by using purposive sampling technique. This was required in order to match the students as a part of the randomization process; thus, only the PG students of the CBCS Programmes of the Dibrugarh University were selected for the final sample of students. From each Department, 30 students were considered for the study through Incidental Sampling technique. So, a total of 300 sample units of population were taken for the study.

Utmost care was taken by the investigator to make the sample representative and comprehensive, while it was being prepared. The sample of the present study comprised the following-

Table 3.3.1: Sample of the Present Study

\begin{tabular}{|c|c|c|}
\hline $\begin{array}{l}\text { SL. } \\
\text { NO }\end{array}$ & DEPARTMENTS & TOTAL \\
\hline 1 & Department of Commerce & 30 \\
\hline 2 & Department of Education & 30 \\
\hline 3 & Department of Physics & 30 \\
\hline 4 & Department of History & 30 \\
\hline 5 & Department of Political Science & 30 \\
\hline 6 & Department of English & 30 \\
\hline 7 & Department of Sociology & 30 \\
\hline 8 & Department of Mathematics & 30 \\
\hline 9 & Department of Statistics & 30 \\
\hline 10 & Department of Life Sciences & 30 \\
\hline & TOTAL & 300 \\
\hline
\end{tabular}

\subsection{DELIMITATIONS OF THE STUDY}

\subsubsection{Delimitation in PG Programmes:}

The Sample for the present study was drawn from educational Institutions which offer post graduate level of education under CBCS programme. Therefore only the departments under CBCS programme were included.
3.4.2 Delimitation of the period of study: For the present study, data collection was limited to the period of 2016.

\subsection{COLLECTION OF DATA}

For the collection of data from the sampled departments, the investigator first of all contacted the Head of the selected Departments to 
take permission for administering the tests. The investigator began to collect data from 15.09.2016 and it was ended in 3.10.2016.

\subsection{STATISTICAL TECHNIQUE USED}

Taking into consideration the objectives and hypothesis of the study, the following statistical techniques were used for the analysis and interpretation of the data:

3.6.1 To study objective no. 1 mean, median, standard deviation, skewness and kurtosis were computed.

3.6.2 For objective 2 qualitative analysis was done.

\subsection{ANALYSIS AND INTERPRETATION OF DATA}

After the collection of data, the next step is proper analysis and interpretation of data. In the present study, the investigator has tabulated the data and analyzed it objective-wise. The investigator tested the null-hypothesis at 0.05 level.

Objective 1: To study the levels of stress of post graduate students of Dibrugarh University.
The first objective of the present study was to study the levels of stress of post graduate students of Dibrugarh University. In order to find out the level of stress among post graduate students here, the investigator had analysed the data getting via PSS-14 scale from the total respondents of 300 using descriptive statistics mainly by computing the Mean, Median and Standard Deviation along with skewness and kurtosis. Here, the investigator had used MS Excel as well as the Statistical Package for the Social Sciences (SPSS version 16.0) software in order to do all of the above statistical analysis. After getting all the 300 individual scores, the investigator compiled all the data and computed the mean, median, standard deviation, skewness and kurtosis. The investigator had also classified the scores into five categories (by going through a standardized procedure of separating a given group into subgroups according to capacity, when the trait is normally distributed) in order to compute the levels. After that, percentages of all the categories were computed in order to find out the exact percentage of each of the category. Below is the table that shows the statistics.

Table 3.7.1: Levels of Stress of P.G. students of DU

\begin{tabular}{|c|c|c|c|c|c|c|}
\hline Variable & Sample (N) & Mean & Median & SD & Skewness & Kurtosis \\
\hline $\begin{array}{c}\text { Level of stress of } \\
\text { P.G. students of DU }\end{array}$ & 300 & 27.97 & 28.00 & 5.748 & -0.44 & 0.845 \\
\hline
\end{tabular}

From the above Table 3.7.1, the Mean, Median, and Standard Deviation of the total 300 scores of PG students studying in Dibrugarh University were found to be 27.97, 28.00 and 5.748 respectively. The value of skewness was -0.44 ; thus the scores were negatively skewed, i.e. majority of the PG students scored high in PSS-14 scale. The value of kurtosis for the sample was 0.845 which was higher than normal curve (.263). It indicates that the distribution of scores was platykurtic in nature; i.e. the curve is flatter than the normal curve. The study revealed the findings (from figure 1) that majority of the PG students
(151) scored in the range of 25-31 (class interval). Similarly, (73) students scored in the range of 3238. Again a total number of (58) student scored in the range of 18-24 and a number of (13) student scored in the range of below 17 and (5) students scored in the range of 39 and above. Hence, the distribution of PSS-14 scores obtained by the PG students of Dibrugarh University was found to be negatively skewed; i.e. majority of the students scored higher than the average (higher in the right side of the average than the left side). Below is shown the frequency distribution table in (figure 1) that indicates percentages and total number of 
respondents of each of the category as well as class intervals.

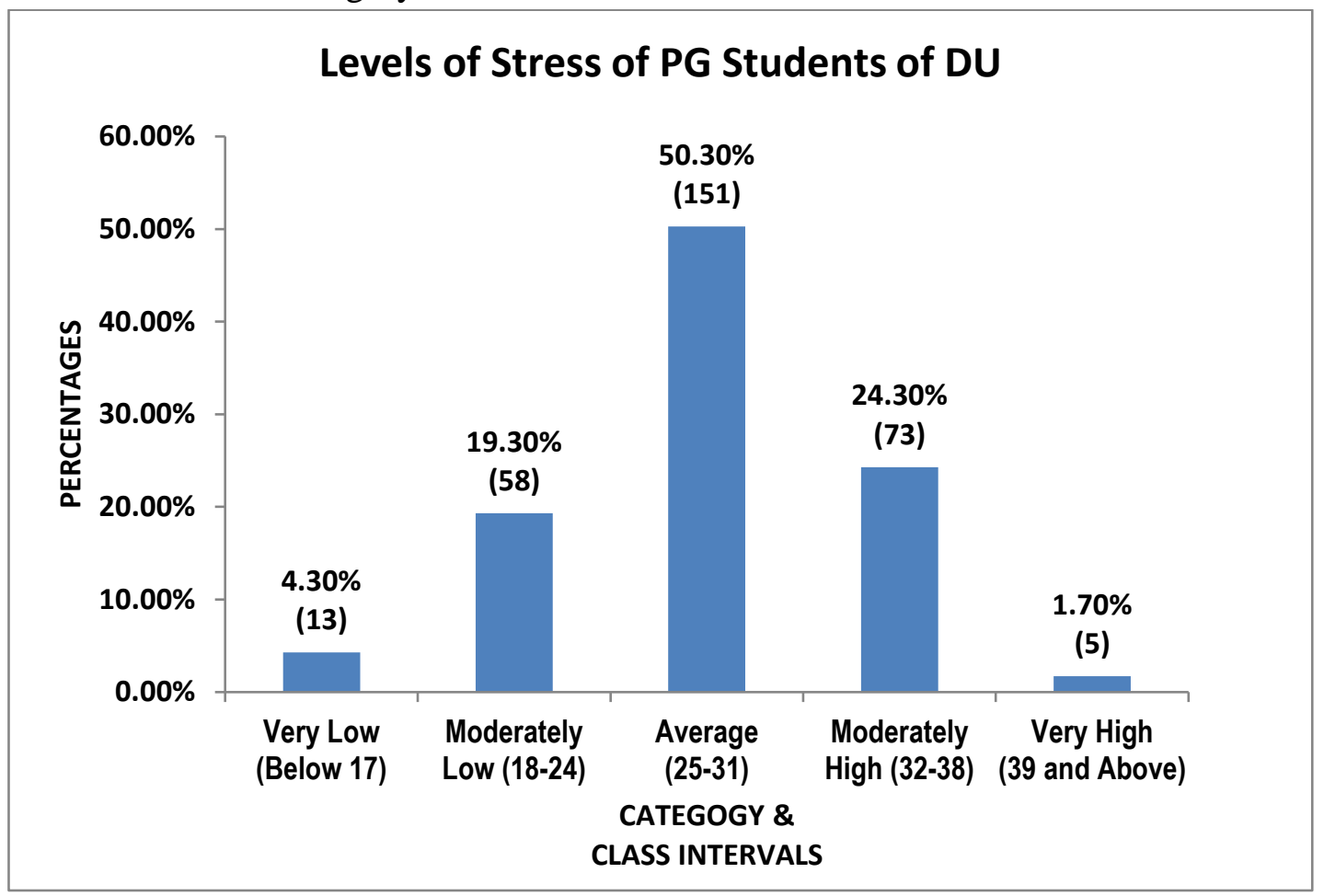

Figure 1: Levels of Stress of PG Students of DU

From the above figure 1 it is found that $50.30 \%$ of student from the total sample of 300 students lies under the category of Average, where 151 students scored in the range of 25-31. Similarly $24.30 \%$ of student lies under the category of Moderately High, where 73 students scored in the range of 32-38. Besides these, $19.30 \%$ of student lies under the category of Moderately Low, where 58 students scored in the range of 18-24. A low percentage of students i.e. $4.30 \%$ and $1.70 \%$ lies under the category of Very Low and Very High respectively, where $\mathbf{1 3}$ and 5 students scored in the range of 17 and below and 39 and above respectively.

Objective 2: To suggest measures to overcome stress among students.

- Study more effectively (Do Smart Work).

- Find ways to calm down. Do exercise, Yoga etc.

- Maintain your daily diet (Improve your diet). Eat well and eat properly. For example, too much caffeine can exacerbate the physical symptoms of test anxiety.
- Get enough sleep (Go to sleep early and get up early).

- Exercise regularly. Exercise can release tension, and the less tension you feel as you go into the test, the better off you might be.

- Smile more often and find reasons to be optimistic. Remember smile is the first sign of happiness and the more you become happy, the less you experience stress.

- Try to avoid using Smartphone (Social Media). Don't let social media fool you.

- Enjoy the little things in life.

- Practice different methods of Positive Psychology.

\subsection{FINDINGS OF THE STUDY}

3.8.1 Majority of the PG students scored higher than the average (higher on the right side than the left side of the average) hence, the scores were negatively skewed. Again the value of kurtosis indicated that the distribution of scores was platykurtic in nature.

3.8.2 Majority of the PG student i.e. (151) scored in the range of 25-31 (class interval). 
Similarly, (73) students scored in the range of 32-38. Again a total number of (58) student scored in the range of 18-24 and a number of (13) students scored in the range of 17 and below and (5) students scored in the range of 39 and above.

3.8.3 $50.30 \%$ of student from the total sample of 300 lies under the category of Average and $24.30 \%$ of student lies under the category of Moderately High. Besides these, $19.30 \%$ of student lies under category of Moderately Low. A very low percentage of students i.e. $4.3 \%$ and $1.7 \%$ lie under category of Very Low and Very High respectively.

\subsection{Conclusion:}

In conclusion, the results are suggestive as to the necessary components of a stress management program specific to the needs of PG students, university administrators should consider incorporating stress management training in orientation activities. At a minimum, the sources of stress identified as the most common could be discussed with incoming freshman, Furthermore, students should be informed of the campus resources available to help them address these resources. A better approach may be the use of a stress management workshop, specifically geared to the stressors encountered by PG students, certainly, stress in the university setting cannot be eliminated but we can and should do a better pre university preparing programme to make our students to know how to deal with it.

\section{References:}

[1] Agolla, J. E., \& Ongori, H. (2009). An assessment of academic stress among undergraduate students: The case of University of Botswana, 4 (February), 63-70. DoR. 10.7.2019 from www.academicjournals.org/article/artic le

1379600680_Agolla\%20and\%20Ongori .$p d f$
[2] Akgun, S., \& Ciarrochi, J. (2003). Learned resourcefulness moderates the relationship between Academic Stress and Academic Performance.

[3] Altmaier, E. M. (1983). Helping students manage stress. San Francisco: Jossey-Boss Inc. Behere, S.P., R. Yadavand P.B. Behere, (2011). A comparative study of stress among students of medicine, engineering, and nursing. Indian Journal of Psychological Medicine, 33(2): 145148.

[4] DoR. 12.07.2019 from http://www.ijpm.info/text.asp?2011/33/ 2/145/92064

[5] Britz, J., Pappas, E., (2010). Sources and outlets of stress among university students: correlations between stress and unhealthy habits. James Madison University. URJHS Vol. 9. DoR. 17.07.2019 from www.kon.org/urc/v9/ britz.html

[6] Chatterjee, S.K. (2012). Educational Psychology. Arunabha Sen books \& allied (p) ltd: 8/1 Chintamoni Das Lane, Kolkata. 700009.

[7] Chakravarty, E. (2013). " Stress - The edge to be Trivialised "With Special Context to Management of Stressed Students Of the Higher Educational Institution, (1977), 25-29. DoR. 12.08.2016 from www.irdindia.in/journal_ijrdmr/ pdf/vol2_iss2/6.pdf

[8] Chen, H., Y. Wong, M. Ran and C. Gilson (2012). Stress among shanghai university students. Journal of Social Work, 9(3): 323-344. DoR. 17.07.2019 from

jsw.sagepub.com/content/9/3/323.refs

[9] Cohen S. Perceived Stress Scale: Measuring the self perception of stress, Redwood City, C: Mind Garden Inc; 1994. DoR. 10.07.2019 from 
https://www.mindgarden.com/document s/PerceivedStressScale.pdf

[10] Cohen, S., Kamarck, T. \& Mermelstein, R. (1983). A global measure of perceived stress. Journal of health and social behaviour, Vol. 24(4), 385-396.

[11] Garrett, H. E. (2013). STATISTICS IN PSYCHOLOGY AND EDUCATION (Third Indian Reprint). Delhi: Surjeet Publication.

[12] Goddard, W \& Melville, S. (2004). Research Methodology: An Introduction. Lansdowne: Juta and Company Ltd.

[13] Gulzar, S., Yahya, F., Nauman, M., Mir, Z., \& Mujahid, S. H. (2012). Frustration among University Students in Pakistan, 1(4), 7-15. Dor. 9.07.2019 from www.aessweb.com/pdf-files/428442.pdf

[14] Hamaideh, S., (2011). Stressors and reaction to stressors among university students. International Journal of Social Psychiatry, 57(1), 69-80. DoR. 17.07.2019 from http:isp.sagepub.com/content/57/1/ 69.abstract

[15] Harlina, H, Siraj, Salam A, Roslan R, Hasan NA, Jin TH, Othman MN,. Stress and Its Association with the Academic Performance of Undergraduate Fourth Year Medical Students at Universiti. (2014), 13(1), 19-24. DoR. 16.07.2019 from

www.iiumedic.net/imjm/v1/download/... /IMJM\%20Vol\%2013\%20No\%201\%20 p19-24.pdf

[16] Kadapatti, M. G., \& Vijayalaxmi, A. H. M. (2012). stressors of academic stress a study on pre-university students, 3(1), 171-175. DoR. 16.07.2019 from www.ijsr.in/upload/428127980Paper\%2 0\%2030.pdf

[17] Kumar, V., \& Kumar, S. (2009). Depression, Anxiety and Stress among the Indian and Iranian Students. Journal of the Indian Academy of Applied Psychology. 35(1), 33-37. DoR. 11.07.2019 from https://www.rairarubiabooks.com/ related-pdf-depression-anxiety-stress001.html

[18] Kumar, M., Sharma, S., Gupta, S., Vaish, S., \& Misra, R. (2014). Effect of stress on academic performance in medical students - a cross sectional study, 58(1), 81-86. DoR. 17.07.2019 from www.ijpp.com/IJPP\%20archives/2014_ 58_1_Jan\%20-\%20Mar/81-86.pdf

[19] Kumari, M.R., Garita, R., (2012). Relationship between stress and academic achievement of senior secondary school students. Asian Journal of Multidimensional Research, 1(3), 152-160. DoR. 16.07.2019 from http://www.tarj.in

[20] Laurence, B. Williams, C. and Eiland, D. (2009) The Prevalence and Sociodemographic Correlations of Depression, Anxiety, and Stress among a group of university students. Journal of American Health.58. 94-105.

[21] Mazumdar, H., Gogoi, D., Buragohain, L., \& Haloi, N. (2012). A Comparative study on stress and its contributing factors among the Graduate and Post-graduate students, 3(1), 399-406. DoR. 17.07.2019 from www.pelagiaresearchlibrary.com/ advances-in-applied.../AASR-2012-3-1399-406.pdf

[22] Nandamuri, P. P., Ch, G., (2009) Sources of academic stress - a study on management students. A.P. India, 506001. 31-41. DoR. 11.07.2019 from www.jms.nonolympictimes.org/Articles 14.pdf

[23] Paramita, P., Das, P., \& Sahoo, R. (2012). Stress and depression among post graduate students, 2(7), 1-5. DoR. 12.07.2019 from www.ijsrp.org/ research_paper_jul2012/ijsrp-july- 
2012-52.pdf

[24] Pandya, B. U. (n.d.). A study on impact of academic stress on mba students of gujarat technological university, 3(July 2012), 20-28. DoR. 12.07.2019 from www.researchersworld.com/vol3/issue3 /vol3_issue3_3/Paper_03.pdf

[25] Pfeiffer, D. (2001). Academic and environmental stress among undergraduate and graduate college students: A literature review, 1-29. DoR. 16.07.2019 from www2.uwstout.edu/content/lib/thesis/20 01/2001pfeifferd.pdf

[26] Quyen, D. (2007). DEPRESSION AND STRESS AMONG THE FIRST YEAR MEDICAL STUDENTS IN UNVERSITY OF MEDICINE AND PHARMACY HOCHIMINH CITY, VIETNAM. DoR. 11/06/2019 from https://www.gembeta.org/public/Downl oadMeasure.aspx?mid=103

[27] Rafidah, K., Azizah, A., Norzaidi, M. D., Chong, S. C., Salwani, M. I., \& Noraini, I. (2009). The Impact of Perceived Stress and Stress Factors on Academic Performance of Pre-Diploma Science Students: A Malaysian Study, 2(June), 13-26. DoR. 15.07.2019 from www.ijsre.com/Vol,\%202_1_-

Rafidah,\% 20et\%20al.pdf

[28] Rajasekar, D. (2013). Impact of academic stress among the management students of amet university - an analysis, (June). DoR. 16.07.2019 from www.ametjournal.com/attachment/Ame tjournal5/5\%20Rajasekar\%2016-813.pdf

[29] Shkulaku, R. (2015). Student's stress in higher educatio $n$ institutions : a critical review of foreign literatures and the ones in albania. Rudina Shkulaku, $\mathrm{PhD}$ Candidate, 7881(August), 40-48. DoR. 16.07.2019 from www.eujournal.org/index.php/esj/articl e/download/6135/5919
[30] Shkullaku, R. (2015). The relationship between stress and academic performance with the Albanian students, II(10), 13698-13714.

[31] Talib, N., \& Zia-ur-rehman, M. (2012). Academic performance and perceived stress among university students, 7(5), 127-132. DoR. 14.07.2019 from http://doi.org/10.5897/ERR10.192

[32] Thawabieh, A. M., \& Qaisy, L. M. (2012). Assessing Stress Among University Students. American International Journal of Contemporary Research, 2(2), 110-116. DoR. 16.07.2019 from www.aijcrnet.com/journals/Vol_2_No_2 _February_2012/13.pdf

[33] Weightman, J., (1999). Introducing organizational behavior. London: Longman.

\section{Web links}

[34] http:/www.mssv.co.in

[35] http://explorable.com/reaearchmethodology

[36] http://study.com/academy/lesson/enviro nmental-stressors-examples-definitiontypes.html

[37] http://www.stress.org/what-is-stress/

[38] www.academicjournals.org/err/PDF/Pdf \%202009/Feb/Agolla\%20and\%20Ongor i.pdf 